\title{
Colocar-se na obra literária: uma leitura dos que estão à margem
}

\author{
Put yourself in the literary work: a Reading of those who are on the border
}

\author{
Ísis Lopes de Almeida \\ Universidade de Santa Cruz do Sul - UNISC - Santa Cruz do Sul - Rio Grande do Sul - Brasil
}

\section{Eunice Terezinha Piazza Gai}

Universidade de Santa Cruz do Sul - UNISC - Santa Cruz do Sul - Rio Grande do Sul - Brasil

Resumo: Neste trabalho, desenvolvemos a ideia de que a filosofia hermenêutica contempla uma atitude moral de empatia, de colocar-se no lugar do outro, através da leitura do texto literário. Sob essa perspectiva, discorremos acerca da situação de opressão de duas personagens ficcionais - Popróshin, de "Diário de um louco", narrativa de Nikolai Gógol, e o louco do Cati, da obra de mesmo título de Dyonelio Machado. Os seres humanos apresentados nestas histórias são levados à loucura por realidades sociais opressoras, injustas e violentas, o que sensibiliza o leitor. Consideramos que, ao debruçar-se sobre as questões da natureza humana, a hermenêutica aponta para as possibilidades que o ser tem de existir e permite ao intérprete a oportunidade de outrarse na construção da compreensão, ampliando seu horizonte de sentidos. Tal ponto de vista interpretativo requer que o leitor se coloque na obra para poder escutá-la, já que o que é pesquisado não se separa daquele que pesquisa. Assim, como aporte teórico, baseamo-nos nos pressupostos da filosofia hermenêutica, sobretudo de Hans-Georg Gadamer e de Ernildo Stein, nas ideias concernentes ao tema da tradução de Jacques Derrida, além de autores que possam contribuir para uma reflexão acerca da violência e da loucura.

Palavras-chave: Hermenêutica. Empatia. Alteridade. Personagens literárias.

\begin{abstract}
In this paper, we developed the idea that the hermeneutic philosophy contemplates a moral attitude of empathy, of putting yourself in the other's spot, through the literary text. From this perspective, we discussed the oppressive situation of two fictional characters - Popróshin, from "Diário de um louco", story by Nikolai Gógol, and the madman from Cati, from the same title by Dyonelio Machado. The presented human beings in these works are driven into madness by oppressive unfair and violent social realities that touch the reader. We consider that, bowing down on human nature questions, the hermeneutic points to other possibilities that the being has to exists and allows the interpreter an opportunity to exchange oneself in the construction of understanding, increasing its horizons of meanings. Such an interpretative point of view requires the reader to put himself in the work in order to hear it, once what is researched is not separate from the researcher. Thus, as theoretical basis, we based ourselves on the assumptions of hermeneutic philosophy, especially with Hans-Georg Gadamer and Ernildo Stein, on the ideas concerning the theme of translation by Jacques Derrida, and authors who can contribute to a reflection of violence and of madness.
\end{abstract}

Keywords: Hermeneutics. Empathy. Otherness. Literary characters. 


\section{Introdução}

Nikolai Vassílievitch Gógol (1809 - 1852) é um dos nomes fundamentais da literatura russa. Autor de contos, novelas, peças de teatro e um romance, é considerado por muitos o mais nacional dos escritores russos por voltar-se, em suas obras, à cultura popular de seu país. Sua prosa, carregada de exageros e dos elementos rasteiros da vida comum, penetra nas mais profundas camadas sociais para desvelar a natureza humana através do riso. O universo gogoliano, por conseguinte, não se baseia em apenas retratar a realidade russa, mas em recriá-la. Arlete Cavaliere, crítica e estudiosa da obra do autor, sublinha que Gógol tinha um "olhar poético" para ver o mundo e as coisas, algo como uma "ótica desautomatizante": "O mundo que o cerca se apresenta não raramente transformado, como se a realidade, filtrada pela imaginação criadora do autor, resultasse em quadros do mundo exterior simultaneamente realistas e fantasticamente transformados" (CAVALIERE, 2009, p. 37).

Em "Diário de um louco", de 1835, temos um bom exemplo desse estranhamento narrativo característico de Gógol. O conto, estruturado em forma de diário, apresenta a evolução da loucura do protagonista, Akcênti Ivânovitch Popróshin. Conselheiro titular encarregado de copiar documentos e consertar penas em uma repartição pública, Popróshin encarna a personagem que, tamanha a sua insignificância social, beira o ridículo. Oprimido por um contexto que sufoca o homem enquanto pensador, por uma realidade extremamente burocratizada e pelos costumes contranaturais dominantes na sociedade russa da época, Popróshin manifesta na loucura uma fuga de sua existência miserável. Nesse sentido, os movimentos absurdos da personagem são dotados de autenticidade e lucidez, provocando a compaixão do leitor.
Dyonelio Machado (1895 - 1985), por sua vez, integra a literatura brasileira, tendo vivido no Rio Grande do Sul. Escreveu romances, contos, memórias e ensaios, além de dedicar-se ao jornalismo e à medicina - possuía especialização em psiquiatria e neurologia. Suas obras são marcadas pelos aspectos sociais da dimensão humana, por personagens marginalizadas que sobrevivem em contextos de pobreza e violência. São personagens que, desajustadas e inseridas em situações de opressão, fome e angústia, despertam a simpatia do leitor por sua humanidade.

Personagens estranhas, como o protagonista d'O louco do Cati, de 1942. Sem nome, sem voz e sem lugar no mundo, o louco do romance de Dyonelio se deixa conduzir ao longo da narrativa por um grupo de rapazes que decide fazer uma viagem até o litoral. Sujeito passivo e em estado de constante alheamento, é apelidado pelos outros de Cati, sendo isto tudo o que o louco é capaz de dizer em momentos de súbito desespero: "É o Cati!". A loucura, nesse caso, tem motivos nas experiências traumáticas da infância e desenvolve-se ao longo de toda uma vida de miséria e humilhação em que o homem se animaliza para sobreviver, de repressão política e social. O louco é então assombrado pelo quartel do Cati $^{1}$ e suas lembranças de horrores e torturas.

Por conseguinte, temos dois escritores separados por culturas bastante distintas e por 43 anos entre a morte do primeiro e o nascimento do segundo, e que parecem pouco ter em comum. Entretanto, com o estudo de suas obras, percebemos que ambos ressaltam a figura do "homem insignificante", socialmente nulo. Gógol com Popróshin e Dyonelio com o seu louco do Cati criam narrativas em que a pequenez do homem nos submundos sociais sensibiliza o leitor. Os seres humanos apresentados nestas narrativas são levados à loucura, sobretudo, por realidades sociais opressoras, injustas e violentas.

da parte uruguaia. Seu comandante foi João Francisco Pereira de Souza, conhecido como "Hiena do Cati", figura de destaque na história política e militar do Rio Grande do Sul. O quartel foi dissolvido em 1908 e seu comandante exonerado no ano seguinte. 
Nesse sentido, podemos afirmar que tanto Gógol quanto Dyonelio manifestam sensibilidade para os dramas humanos, focalizando especialmente os sujeitos que buscam dentro de si formas de enfrentar uma realidade assustadora e apelando assim à humanidade do leitor. Aqui, a hermenêutica, por contemplar uma atitude moral de empatia, de colocarse no lugar do outro a fim de ampliar os possíveis sentidos da interpretação literária, parece proporcionar-nos uma perspectiva preciosa não apenas do texto, mas da própria natureza humana, do universo em que nos inserimos.

Por conseguinte, a obra ficcional é um outro que desejamos compreender - que interpretamos por meio da leitura e, também, de um processo de tradução. Em vista disso, nossa base teórica concernente ao campo hermenêutico passa por Jacques Derrida (Torres de Babel, 2002), Ernildo Stein (Aproximações sobre hermenêutica, 1996) e Hans-Georg Gadamer ("Ler é como traduzir", 2010), revelando as pontes existentes entre interpretação e tradução e destacando em que aspectos elas podem aprofundar nosso trabalho com os textos literários.

\section{Considerações acerca das premissas teórico/epistemológicas para a abordagem dos textos ficcionais}

Começamos pela obra de Jacques Derrida, Torres de Babel (2002), que, embora trate do tema da tradução, diz muito sobre o processo interpretativo, visto que toda tradução requer uma interpretação e que toda interpretação envolve certa tradução enquanto desvendamento e elaboração de sentidos.

O texto de Derrida toma como base o mito da torre de Babel - ou, conforme assinala, a história da origem da confusão das línguas que se espalharam pelo mundo. De acordo com o mito que Derrida (2002) retoma, Deus teria se enfurecido com a ousadia dos homens em construírem uma torre de mais de 25 mil metros, unidos sob uma única língua, e os dispersado de modo que um homem não mais compreendesse a língua de seu próximo. Dessa dispersão, na forma da desconstrução de um idioma único, teria se originado a multiplicidade das línguas, e, com ela, a necessidade da tradução.

Entretanto, para Derrida (2002), há aí uma impossibilidade imanente. Segundo o autor, a torre de Babel

[...] não configura apenas a multiplicidade irredutível das línguas, ela exibe um nãoacabamento, a impossibilidade de completar, de totalizar, de saturar, de acabar qualquer coisa que seria da ordem da edificação, da construção arquitetural, do sistema e da arquitetônica. $O$ que a multiplicidade de idiomas vai limitar não é apenas uma tradução "verdadeira", uma entr'expressão transparente e adequada, mas também uma ordem estrutural, uma coerência do constructum ( $p$. 11-12).

Assim, embora a tradução seja necessária na busca pela compreensão, o elemento da multiplicidade a torna sempre inconclusa. Sob essa perspectiva, há algo no texto original que permanece inapreensível enquanto totalidade, apenas vislumbrado, tocado de leve, por melhor que se mostre o trabalho do tradutor. Mas então, Derrida (2002) questiona, qual seria a tarefa essencial da tradução? A que poderia almejar o tradutor? Nesse ponto, o autor resgata o texto de Walter Benjamin, "Die Aufgabe des Übersetzer" (ou "A tarefa do tradutor"), a fim de melhor fundamentar as questões às quais se propõe.

Derrida (2002) destaca que, na concepção benjaminiana, o tradutor é um endividado, já que seu trabalho consiste em devolver o que devia ter sido dado, em restituir um sentido. Em outras palavras, o tradutor pode ser considerado como um sujeito "[...] obrigado por um dever, já em situação de herdeiro, inscrito como sobrevivente dentro de uma genealogia, como sobrevivente ou agente de sobrevida" (DERRIDA, 2002, p. 33). Contudo, o autor de Torres de Babel (2002) ressalta: não se deve entender o tradutor nem como um receptor, nem como alguém que tenha o intuito de comunicar qualquer mensagem, nem como um sujeito que copia ou reproduz um original.

A finalidade da tradução consiste, por conseguinte, em exprimir a relação mais íntima entre as línguas. Para Derrida (2002), a tradução "[...] não buscaria dizer isto ou aquilo, a transportar tal ou tal 
conteúdo, a comunicar tal carga de sentido, mas a remarcar a afinidade entre as línguas" (p. 44). Nesse sentido, torna-se capaz de exibir sua própria possibilidade de uma convergência original, uma vez que, conforme argumenta o autor, as línguas não são estrangeiras umas às outras, mas aparentadas. A verdade à que pode aspirar uma tradução, portanto, não reside em uma correspondência representativa entre o texto original e o texto traduzido, mas significa a "linguagem pura" - nos termos de Derrida (2002) na qual o sentido e a letra não se dissociam mais.

Mas passemos então às obras literárias que, embora não sejam as línguas babélicas, são criações humanas que possuem uma história e uma voz. Nessa perspectiva, assim como o tradutor, o intérprete possui a tarefa de escutar o que a obra diz para poder compreendê-la, de percebê-la em sua relação com as demais obras, em sua existência de mundo. Em ambos os contextos, resguardadas as distintas especificidades de cada área de estudo, o que se busca são possíveis sentidos, possíveis horizontes interpretativos que permitam ao tradutor e ao intérprete descobrir determinado texto. É então que Torres de Babel (2002) torna-se basilar a este trabalho.

Encontramos, no campo da filosofia hermenêutica, pressupostos que se alinham às considerações tecidas por Derrida (2002), tal como a impossibilidade de uma interpretação acabada da obra literária. De acordo com o hermeneuta Richard Palmer (2011), a compreensão de uma obra - enquanto voz humana carregada de influências, de relações e de possibilidades - passa por uma espécie de encontro histórico que apela para a experiência pessoal de quem está no mundo. Não se trata, nesse caso, de uma compreensão de conteúdos objetivos, mas de uma compreensão mais ampla que diz respeito à condição humana.

Por conseguinte, a filosofia hermenêutica aborda o mundo sob determinado discurso, sob determinada perspectiva e sob determinado contexto. Isso remete aquele que interpreta à questão da inesgotabilidade. Conforme argumenta Ernildo Stein (1996), falar sobre o mundo é o mesmo que falar sobre algo que não se limita. Toda proposição pressupõe uma história e uma cultura, logo, permite uma interpretação. E, onde há interpretação, pode haver divergências, afirma Stein (1996). Por isso, ao invés de nos empenharmos em estabelecer uma verdade absoluta, a sugestão do autor é para que nos dediquemos a mostrar as razões e os caminhos pelos quais divergimos.

Assim como, para Derrida (2002), a multiplicidade interdiz uma tradução "verdadeira", para a perspectiva hermenêutica, as individualidades implicadas em uma obra literária afastam a interpretação de uma verdade incontestável. Segundo Stein (1996), no universo das teorias hermenêuticas, a busca pelo sentido apresenta-se como mais válida do que a busca por uma suposta verdade absoluta. $O$ autor destaca que, "[...] com o nascimento da tradição hermenêutica, começamos a perceber que os diversos campos da filosofia, que antes eram determinados a partir do mundo natural, poderiam ser multiplicados ao infinito através da inventividade humana" (STEIN, 1996, p. 39).

Além disso, conforme observamos em Derrida (2002), o tradutor não é um simples operário, não copia o texto original em sua tradução, mas Ihe dá fisionomia própria por meio de um labor artesanal. De forma semelhante, o intérprete não é aquele que extrai significados da obra literária como um cientista que disseca seu objeto de pesquisa, mas aquele que se coloca no universo da obra para escutá-la, uma vez que, do ponto de vista hermenêutico, a compreensão engloba os modos que o homem tem de existir no mundo. Trata-se aqui também de uma tentativa de outrar-se, no sentido proposto por Emmanuel Lévinas.

Gostaríamos ainda de mencionar alguns pontos do texto de Gadamer, "Ler é como traduzir" (2010), pois julgamos que complementam e lançam novas luzes ao assunto aqui discutido. Nesse texto, um dos primeiros pressupostos abordados pelo autor refere-se à intraduzibilidade da obra literária. Gadamer (2010) aponta que prestar contas sobre o que se perde no processo de tradução é tão ou mais importante do que refletir sobre aquilo que se conquista, e lembra que, para Benedito Croce, toda tradução é uma traição "traduttore-traditore". 
A respeito desse caráter de difícil apreensão da linguagem, Gadamer (2010) argumenta que

[...] o próprio falar jamais é dotado de uma exatidão tão plena que sempre se escolhe e encontra a palavra correta. No diálogo já há muitas falas que não ficam senão dando voltas, e o mesmo acontece no texto em meio à busca por um subterfúgio nas formas vazias da retórica trivial (p. 125).

Assim, o conceito de intraduzibilidade proposto pelo autor dialoga com as ideias da impossibilidade da tradução e da inesgotabilidade da interpretação, conforme exposto anteriormente. Gadamer (2010) também deixa claro que, apesar das barreiras e interdições que se apresentam ao tradutor e intérprete, a compreensão é sempre o fim ao qual o texto visa. Esta compreensão, para o autor, passa por diversos níveis de exigência linguística $e$, no caso das obras literárias, depara-se com um grau de intraduzibilidade que "[...] ergue-se de maneira ameaçadora como uma montanha gigantesca dotada de muitas camadas" (GADAMER, 2010, p. 129).

Por conseguinte, a tradução de uma narrativa não necessita apenas ser legível, mas, segundo Gadamer (2010), manter presente a respiração daquele que fala, a respiração que anima a compreensão. A questão fundamental da tradução enquanto busca de sentidos abarca, portanto, muito mais do que determinada escolha de palavras: envolve "[...] a concretude plástica, a concentração da tensão, a profundidade da alma, a magia do mundo" (GADAMER, 2010, p. 129). Nesse ponto, somos também remetidos às considerações hermenêuticas de Stein (1996) quando assinala que o que a interpretação da obra ficcional proporciona é sobretudo uma experiência de mundo.

Por fim, está aqui incluso o elemento criador, tanto para o tradutor como para o intérprete - ou para - leitor que compreende, nas palavras de Gadamer (2010). A ambos é dado criar uma nova totalidade textual a partir de som e sentido, de uma conversão de signos em pontes de compreensão que podem resultar em ganhos ou perdas. Ler e traduzir são, portanto, interpretação e, conforme sugere Gadamer (2010), apresentam a mesma performance hermenêutica.
De fato, tanto a filosofia hermenêutica como a teoria da tradução aqui esboçadas parecem oferecernos caminhos bastante apropriados no trato de temas literários que versam sobre o humano consequentemente, sobre o ambíguo e impalpável. Como dar por acabada, por última, uma interpretação que concerne ao homem - esse que é um e tantos outros? Derrida (2002) nos faz ver que não podemos alcançar o elemento intocável da existência humana, mas que é justamente ele que fascina e que orienta o trabalho do tradutor. Mas também do intérprete, aquele que deseja e que necessita compreender. Por conseguinte, na tentativa de colocarmo-nos no lugar do outro através da leitura dos textos literários, pensamos que as considerações dos autores mencionados até aqui nos auxiliam a perceber 0 mundo a partir de um ponto de vista ético perante esse outro.

\section{Sociedade, violência e loucura}

Coloquemo-nos então nas obras de Gógol e de Dyonelio Machado - enquanto intérpretes, enquanto tradutores ou enquanto sujeitos que não se separam da totalidade do texto - para escutarmos o que elas têm a dizer. Aqui, por meio de uma abordagem direcionada às trajetórias das personagens principais dentro das narrativas, buscamos contextualizar situações de violência sistêmica sobre os indivíduos e desenvolver a perspectiva de que uma sociedade opressora é capaz de enlouquecer o homem. Nesse sentido, consideramos a existência de uma loucura social que penetra a experiência moderna, de uma loucura que se manifesta no esvaziamento das relações humanas, na violência dos mecanismos sociais e na alienação do homem em um mundo antinatural.

Em "Diário de um louco", Akcênti Ivânovitch Popróshin está no mais baixo patamar social dos pequenos funcionários públicos que habitam as repartições e chancelarias de uma São Petersburgo do século XIX, da São Petersburgo de Gógol. Socialmente nulo e não podendo aspirar a qualquer outra perspectiva de vida senão pelo prisma do 
ridículo, Popróshin anima um contexto de homens insignificantes, miseráveis e humilhados dentro de uma burocracia insossa em que ambições mesquinhas são colocadas acima de qualquer respeito pelo ser humano. Por não vislumbrar sentido nesse mundo, a personagem mostra-se contraditória: detesta os figurões, generais e cadetes, mas gostaria de ser imponente como eles; despreza as relações artificiais e aristocráticas, embora idealize situações em que possa fazer parte delas.

Mas vejamos como isso se dá na narrativa gogoliana. Um dia, Popróshin sai de casa atrasado para o trabalho e, no caminho, avista a filha do chefe a entrar em uma loja. Sofia é uma beldade de olhos cintilantes e ele imediatamente se vê apaixonado por ela. É nesse momento, entre o arrebatamento do amor e a vergonha por estar vestindo um casaco cheio de manchas e fora de moda, que ele percebe algo inusitado. Medji, a cadelinha de Sofia, acaba ficando do lado de fora da loja quando a porta se fecha e começa a conversar com outra cadelinha, Fidel, que vem andando atrás de duas mulheres.

Popróshin observa espantado as duas cadelinhas a falarem como gente e escuta que elas escrevem cartas uma à outra. A fim de saber qualquer coisa de interessante sobre Sofia, descobre onde mora Fidel e rouba as tais correspondências. O conteúdo das cartas, entretanto, mais o revolta do que satisfaz sua curiosidade. As cadelinhas conversam especialmente sobre banalidades, embora tais banalidades carreguem uma certa crítica aos valores da alta sociedade. Popróshin despreza o estilo canino da escrita e, aqui, o leitor deleita-se com a comicidade da obra de Gógol.

O que mais indigna a personagem é descobrir que o pai de Sofia pretende casá-la com um cadete. Popróshin pensa que gostaria de ser um general para meter toda aquela gente "em embrulhadas" e rasga as correspondências. A partir de então, passa a se questionar sobre sua condição - por que precisa ser

\footnotetext{
2 De acordo com Ivo Caggiani (1997), o terror vinculado ao Cati, bem como a fama de violência atribuída ao seu comandante e aos demais militares atuantes no quartel, não correspondem à realidade histórica, figurando de forma mítica apenas no imaginário popular. Por outro lado, ressalta que as mortes por degola foram características no período da Revolução
}

um miserável conselheiro titular? - e chega a cogitar a hipótese de não saber quem realmente é. A dúvida, porém, não se prolonga por muito tempo, pois Popróshin se dá conta de que é o rei da Espanha.

Percebe-se então uma ruptura no ser do protagonista que é refletida na estrutura narrativa do conto. No dia marcado no diário como "Ano 2000, 43 de abril", Popróshin descreve a descoberta de sua real identidade em tom festivo. Vai ao trabalho apenas para zombar de toda a "canalha da chancelaria", comportando-se como um verdadeiro rei, e procura Sofia para dizer-Ihe que agora podem viver juntos. Obviamente, tudo isso é visto como loucura e insensatez pelas demais pessoas e Popróshin acaba sendo levado à força para um manicômio - onde, apesar dos castigos e sofrimentos que the são impostos, ele não deixa de acreditar que é um rei. Suas últimas impressões registradas no diário caminham para um estado de delírio e são perpassadas por um tom lírico.

No caso d'O Louco do Cati, romance de Dyonelio Machado, o protagonista é um sujeito estranhamente passivo. Quase não fala e praticamente não sabemos o que pensa sobre o mundo - situação oposta à que encontramos no diário de Popróshin. Entretanto, conhecemos a origem de sua angústia, de sua incapacidade de se colocar no mundo: o Cati, quartel militar que, em fins do século XIX, teria aterrorizado a região gaúcha da Campanha pela prática de torturas e degolas ${ }^{2}$. O trauma do que viu e experimentou na infância é o que lhe dá nome e então ele fica sendo o louco do Cati. Figura insólita, de "olhar sem conteúdo" e "focinho de cachorro", a personagem vaga entre passado e presente num ar de abandono, embora, ao final da narrativa, nos pareça que, desde o princípio, o louco procurava por si mesmo.

Essa busca, entretanto, é inconsciente para ele. Até os derradeiros capítulos do romance, o louco simplesmente se deixa levar pelas circunstâncias do

Federalista, imediatamente anterior à criação do Cati, e que João Francisco (a Hiena do Cati) foi um exímio chefe militar. Assim, observamos que esses aspectos podem ter contribuído para formar a aura assombrosa que popularmente se manifestou sobre o Cati e que se percebe através da narrativa de Dyonelio Machado. 
que the acontece ao redor ou por qualquer um que simpatize com sua condição. É assim que, tendo tomado um bonde para lugar nenhum e descido no fim da linha, acaba entrando em um bar e dando com um grupo que se prepara para uma viagem até o litoral. Um dos sujeitos percebe que o louco, em sua aura de atarantamento, não tem destino, e decide levá-lo junto. Ele se integra silenciosamente ao grupo. A "caravana" fica, portanto, composta de cinco pessoas, sendo Norberto, rapaz de olhar inteligente, o líder da empreitada e futuro companheiro do louco ao longo da história.

Em um pequeno caminhão Ford apelidado de Borboleta, eles partem de Porto Alegre com a intenção de retornarem no mesmo dia. O louco é considerado inofensivo pelo grupo e segue quieto, o focinho espichado para a frente, ausente de si mesmo, até chegarem a uma hospedaria que ele confunde com o Cati. Em estado de pânico e bracejando num "gesto apocalíptico", o louco grita - "Isto é o Cati!" - e corre para dentro de um mato nas proximidades da hospedaria. Enquanto foge, imaginando-se em um cerco, relembra episódios de sua infância, momentos de medo da violência exercida pelos oficiais do Cati. Os companheiros, que ele vê como perseguidores, encontram-no exausto e aterrorizado, e sentem pena daquele homem que passam então a chamar de Cati. As terríveis lembranças se misturam à realidade na perspectiva do louco e assombram outros momentos de pavor e fuga na trajetória da personagem.

Após o almejado banho de mar, o grupo se separa - Norberto e o louco seguem subindo o litoral gaúcho, rumo à Santa Catarina, enquanto os demais rapazes retornam à capital. Sujeito sinuoso, supostamente envolvido em algum movimento contraventor e designado como "agitador" pela polícia, Norberto é preso e o louco do Cati considerado seu cúmplice. Os dois são então despachados para um presídio no Rio de Janeiro, onde ficam detidos até que Norberto articule a sua soltura e a do companheiro. A parte final da narrativa descreve a longa jornada do louco de volta para casa - jornada que deveria levá-lo outra vez a Porto Alegre, mas que acaba se desviando para os campos da região de fronteira com o Uruguai, para as ruínas do Cati. Uma odisseia para chegar ao lugar do qual o louco tentara sempre fugir.

Por fim, avançando por charcos alagados por dois meses de chuvas e perseguido por um cão de estância, um canzarrão na forma de um lobo, o louco encontra o Cati. Em meio às imagens delirantes do trauma - os dólmãs negros dos oficiais, os restos de um castelo sombrio, os poços medievais em que há gente, um cão fantástico, um lobisomem que é ele mesmo - e ao alívio de saber que não precisa mais fugir, ele compreende tudo. Ele, "[...] o Homem decaído e sobrenatural (lobisomem, semi-homem)" (MACHADO, 2003, p. 256), descobre a verdade sobre si como uma revelação:

Na sua humilhação inferior, quando muito era um... Homem-cachorro! Bem que sentira sempre a sua sofreguidão canina, quando engolia o seu tassalho de carne... os seus silêncios invencíveis de cão... uma vez, que fora encerrado num quarto - como um cachorro!... o olhar triste de animal que erguera, certo dia, para o rosto moreno de Nanci (a mulher) e que tanto a perturbara... E um rabo que abanava, ingênuo, a cada "festa"... - Tudo, assim, havia sido uma "preparação", para aquele momento, - o seu momento. Entrava, como um cão na crise da sua vida. - Tinha medo (e fuzilou o olhar para os lados, procurando um amparo humano na solidão), tinha medo de botar a mão no rosto enxovalhado, e dar com o focinho dum cachorro... (MACHADO, 2003, p. 257).

E apesar de sua "vida ultrajada de espectro", da insignificância do homem degradado que agora percebe ser, o louco do Cati sorri. Está finalmente entregue aos demônios de sua infância, ao lugar que Ihe pertence.

Em suma, a violência está no âmago de ambas as obras aqui abordadas. Observamos, por conseguinte, que Popróshin e o louco do Cati expressam ecos das violências sofridas pela sociedade em que se encontram e que são personagens socialmente marginalizadas tentando superar situações de opressão. Arlete Cavaliere (1986) aponta que o homem que habita as narrativas urbanas de Gógol, por fazer parte de um mundo 
absurdamente burocrático, só pode expressar-se de formas igualmente absurdas: ora alucinado, ora obsessivo, ora suicida ou louco. Para a autora, essa perspectiva reflete o modo como o escritor via a cidade de São Petersburgo. Paulo Bezerra (2013), ao refletir sobre a obra de Dostoiévski - que compartilhou de um período social muito próximo ao de Gógol -, ressalta o homem sufocado e enlouquecido pelo

[...] tipo de relações sociais desiguais dominantes numa sociedade como a russa, na qual uma aristocracia com fortes traços de primitivismo se funde a uma burguesia emergente e primária, para dirigir a coisa pública com um burocratismo bolorento, que lembra uma caverna impermeável à entrada de ar e luz (p. 239)

Assim, no contexto que se delineia em "Diário de um louco", encontramos condições sociais que reprimem e que agridem o ser humano em sua sensibilidade. Os funcionários que se amontoam nos departamentos, empregados para cumprir tarefas puramente burocráticas, são mais instrumentos da máquina pública do que sujeitos conscientes - e como instrumentos, podem ser facilmente descartados e substituídos. O protocolo pelo qual se orientam esses pequenos funcionários consiste, sobretudo, em submeter-se: aos chefes de seção, às pequenas humilhações diárias, à autoridade de uma hierarquia social que os condena a uma existência inferior. Não há espaço para o protesto, senão pelo prisma da loucura, e mesmo ela é sufocada pela violência do encarceramento.

Nesse meio em que imperam moralidades condenáveis, Popróshin é uma figura tão insignificante na sua esfera social que só pode despertar o desprezo alheio, como o do chefe da repartição em que trabalha: "Ora, procure se enxergar, conheça o seu lugar! Não está vendo que não é nada, que é mera insignificância! Que não tem onde cair morto!" (GÓGOL, 1990, p. 64). O próprio funcionário reconhece que, por não possuir recursos, nada pode alcançar. Se fosse um general, por outro lado, sentiria imenso prazer em humilhar toda a gente que o desrespeita - de agredido, passaria a agressor legitimado por um sistema social desumano. Embora a perspectiva de Popróshin seja ambígua, a personagem mostra-se a única capaz de compreender a sociedade doentia em que vive.

No que concerne à realidade social presentificada na literatura de Dyonelio Machado, encontramos aspectos bastante semelhantes. Tanto Popróshin quanto o louco do Cati são sujeitos que sobrevivem à margem, no submundo do esquecimento, mortos para a vida social. Nesse sentido, são mais espectros do que homens. Aqui, aliás, a degradação humana alcança e ultrapassa a fronteira com a animalização - o louco é descrito como um cão que tenta compreender o mundo por meio de um "focinho indagador". Criatura devastada pela experiência da violência, não visto e não ouvido pela sociedade dos homens, só lhe resta cismar sem rumo com "[...] a sua face muda, quase sem carne, de cão..." (MACHADO, 2003, p. 43).

Entretanto, a mudez nem sempre foi uma característica sua. Ela veio com a repressão e o silenciamento impostos na infância, período em que a violência do Cati, como um polvo - assim Norberto costuma descrever o quartel militar -, alcançou-o com seus tentáculos cheios de horrores. Certa vez, viu um preso sendo levado para o Cati e indagou da mãe o que seria feito do homem, ao que ela lhe respondeu: "Psiu! Vão matar ele lá no Cati..." (MACHADO, 2003, p. 29). Noutra ocasião, enquanto os familiares discutiam "casos de injustiça", o tio foi espiar do lado de fora da casa e todos ficaram suspensos num ar de medo. Quando o menino quis saber o que ocorria, a mãe novamente advertiu: "Cala a boca: o Cati!" (MACHADO, 2003, p. 34). Assim, ele aprendeu a temer o Cati e, desde então, foi emudecendo até que tudo o que conseguisse dizer fosse aquilo que mais o apavorava.

Essa impossibilidade de falar como consequência de toda uma existência de violência sistêmica e de humilhação social também está em Popróshin, personagem de Gógol. Quando fica frente a frente com alguém que lhe é socialmente superior, Popróshin não consegue dizer o que deseja e observa que "o diabo da língua" não lhe obedece. Ele apenas se torna capaz de se expressar verbalmente e de modo firme diante de figuras importantes quando a 
loucura se desenvolve e Popróshin passa a se considerar rei. N'O Louco do Cati, a personagem não chega a superar seu silêncio através da loucura, mas, ao retornar à fonte do trauma que a incapacita para a vida, conquista um novo nível de consciência sobre sua condição no mundo.

Sob essa perspectiva, fazem-se relevantes algumas palavras a respeito do trauma em sujeitos submetidos a realidades de violência. Em Catástrofe e representação (2000), Arthur Nestrovski e Márcio Seligmann-Silva discutem as implicações de uma exposição rotineira à violência. Cada pessoa, conforme afirmam os autores, "[...] sobrevive como pode a uma dose diária de exposição traumática, na tela da televisão ou no sinal de trânsito" (p. 11). Recordam, como exemplo dessa situação, das reflexões de Freud sobre os soldados que passaram pelos conflitos traumáticos da Primeira Guerra Mundial:

Ao estudar o caso de soldados austríacos retornando da Primeira Guerra atormentados por suas lembranças, mas incapazes de dizer uma palavra sobre o que viram, Freud define o trauma como "uma experiência que traz à mente, num período curto de tempo, um aumento de estímulo grande demais para ser absorvido". É uma lembrança que o indivíduo não sabe que lembra, mas que se manifesta em atos obsessivos, sem ligação consciente com a atualidade (NESTROVSKI; SELIGMANN-SILVA, 2000, p. 8).

O trauma, por conseguinte, constitui-se como uma ferida na memória. Em uma de suas Conferências introdutórias, Freud (1969) afirma a respeito de pacientes presos a acidentes traumáticos: "É como se esses pacientes não tivessem findado com a situação traumática, como se ainda estivessem enfrentando-a como tarefa imediata ainda não executada" (p. 325). Essas considerações nos ajudam a aprofundar nossa compreensão sobretudo da personagem de Dyonelio Machado, uma vez que, tendo presenciado um evento de violência, não consegue absorver e suplantar o trauma, permanecendo em angustiante conflito com essa experiência através das lembranças.

Já o funcionário público de Gógol é moldado por uma espécie de violência que comumente passa despercebida, que não apenas permeia silenciosamente os mecanismos sociais, mas que se torna necessária na manutenção de sua normalidade. Em Violência (2014), Slavoj Žižek ressalta que, quando pensamos sobre esse tema, pensamos primeiramente em guerras, em atos de crime e de terror explícito. Contudo, como destaca o filósofo, é necessário recuarmos um passo para que possamos perceber os contornos que engendram essas manifestações explosivas: "O passo para trás nos permite identificar uma violência que subjaz aos nossos próprios esforços que visam combater a violência e promover a tolerância" (ŽlŽEK, 2014, p. 17). Assim, o autor designa duas faces da violência: uma subjetiva, visível e exercida por um agente claramente identificável, e outra objetiva, de difícil apreensão.

Žižek (2014) esclarece que

[...] a violência subjetiva é experimentada enquanto tal contra o pano de fundo de um grau zero de não violência. É percebida como uma perturbação do estado de coisas "normal" e pacífico. Contudo, a violência objetiva é precisamente aquela inerente a esse estado "normal" de coisas. A violência objetiva é uma violência invisível, uma vez que é precisamente ela que sustenta a normalidade do nível zero contra a qual percebemos algo como subjetivamente violento (p. 18).

Nesse sentido, compreendemos que, além das agressões físicas às quais Popróshin é submetido no manicômio, a violência está em todo lugar ao longo da narrativa de "Diário de um louco", desde os princípios morais deturpados até a organização hierárquica e aristocrática daquele contexto social. Trata-se aqui da violência exercida por uma sociedade de aparências em que é preciso ter - títulos, posses, educação refinada - para ser. Os que não se mostram aptos para participarem desse sistema, são considerados homens inferiores e excluídos.

Às vezes, loucos.

Há muito tempo, a loucura vem sendo associada à violência pelos aspectos da repressão e do encarceramento. Como lembra Michel Foucault (1997), os hospícios nem sempre se destinaram a 
isolar da sociedade sujeitos realmente insanos, do ponto de vista médico, mas também agitadores, pobres e mendigos, a fim de limpar as ruas de pessoas que representavam um problema social. Ainda hoje a sociedade exclui o louco como aquele que não tem lugar entre os outros e, para Roberson Rosa dos Santos (2012), o homem caracterizado como louco, seja por motivos biológicos, seja pela incapacidade de se inscrever na ordem social institucionalizada, carrega sempre um caráter estigmatizado.

Em Mitologia, loucura e riso (2012), Žižek argumenta que ser humano significa ser potencialmente louco, uma vez que, em termos hegelianos, "[...] a loucura não é um lapso acidental, uma distorção ou 'doença' do espírito humano, mas algo inscrito na constituição ontológica básica do espírito do indivíduo" (ŽlŽEK, 2012, p. 192-193). O filósofo ressalta que tal ponto de vista não significa que todas as pessoas devam necessariamente passar por um estado de demência, mas que a loucura figura como uma possibilidade natural da mente humana: "[...] é algo cuja ameaça deve ser superada para emergirmos como sujeitos 'normais', o que significa que a 'normalidade' só pode emergir como superação dessa ameaça" (ŽıŽEK, 2012, p. 193).

Paralelamente a essa loucura ontológica que necessita ser superada, é possível considerarmos ainda a existência de uma loucura social que penetra a experiência moderna, de uma loucura que se manifesta no esvaziamento das relações humanas, na violência dos mecanismos sociais, na alienação do homem em um mundo de frustração e sofrimento. Assim, em relação às narrativas ficcionais aqui discutidas, este é o momento de nos perguntarmos em que medida as personagens de Gógol e de Dyonelio Machado são de fato loucas.

Não há dúvidas de que Popróshin e o louco do Cati revelam algo de patológico, sinais que indicam a presença de uma loucura enquanto acontecimento - o primeiro com sua crença inabalável em ser rei e com seus delírios; o segundo com suas visões fantasmagóricas do Cati e com a constante obsessão de que será preso e levado para lá. Como exemplos, podemos citar os episódios em que Popróshin, já no manicômio, disserta sobre o pouso que a Terra fará na Lua e sobre a constituição desta, habitada, inclusive, apenas por narizes, e em que o louco do Cati vê na fisionomia de um de seus companheiros de viagem a figura "negra e lendária" de um oficial do temido quartel, o que o faz fugir em disparada. Além disso, na medida em que se aproxima das ruínas do Cati, realidade e imaginação se fundem em uma perspectiva delirante do mundo.

Entretanto, a loucura de ambas as personagens pode ser percebida de forma ambígua. No que concerne ao maluco da narrativa de Dyonelio, o Dr. Castel, médico e professor que o examina, afirma que ele não possui doença alguma, ao mesmo tempo em que diz ser o paciente "incurável". Já o Dr. Valério, com quem o louco do Cati viaja de volta ao Rio Grande do Sul, confessa não poder ter certeza sobre a loucura do sujeito. O fato é que, apesar de sua estranheza, ao final do romance, o louco manifesta uma lucidez surpreendente. Diante do quartel que foi se desfazendo com o tempo, ele compreende no que a violência do Cati o transformou: em um homem-cão, criatura humilhada e indigente. Nesse momento de redenção, o louco do Cati adquire consciência a respeito de sua situação social e da trajetória de sofrimento que o conduziu até ali, da verdade sobre si mesmo.

Em "Diário de um louco", Popróshin também é uma personagem lúcida, a única capaz de ver o mundo sem máscaras, toda a hipocrisia e mesquinhez que o compõem. Por não ser aceito dentro da sociedade dos "figurões", dos homens ilustres, ele pode contemplá-la da margem em que se encontra. Assim, enquanto todos os demais permanecem cegos em suas ambições, o pequeno funcionário público desvela a falsidade das instituições sociais e a superficialidade dos laços humanos a partir de uma perspectiva cáustica, mas coerente. Enquanto a loucura o toma e o transforma em rei espanhol, Popróshin questiona a hierarquia cruel da sociedade russa.

De acordo com o que argumenta Foucault (1997), há sempre uma lógica interna na loucura, de modo que as ideias dos considerados loucos acabam não sendo assim tão desarrazoadas. Desse modo, 
apesar dos delírios e dos atos desajustados pelos quais se expressam as personagens - alguns deles até provocam nosso riso -, compreendemos a legitimidade de suas trajetórias e nos apiedamos delas, nos compadecemos de seu sofrimento. Sua lucidez diante de uma sociedade injusta, que oprime a dignidade humana, desperta nossa empatia.

\section{Conclusão}

A empatia, como uma atitude ética, requer que estejamos dispostos a nos colocarmos no lugar do outro, a tentarmos perceber o mundo a partir de uma perspectiva diversa da nossa. Requer, nesse sentido, que apuremos nossa sensibilidade na tentativa de compreendermos esse outro - seja ele o homem, a personagem de ficção ou o próprio texto literário. Para isso, como viemos salientando ao longo deste estudo, realizamos uma abordagem hermenêutica que nos permite a escuta daquele que fala. Quando, porém, desconsideramos ou silenciamos o outro, incorremos no âmbito da violência.

Assim, emudecido pelas experiências traumáticas da infância e tornado menos que um homem, um homem-cão, pela vida marginalizada, o louco do Cati não possui nem mesmo um nome na narrativa de Dyonelio Machado. Ao invés disso, carrega consigo a memória dos muitos homens liquidados pela violência do lendário quartel militar. $O$ funcionário público Popróshin, também uma criatura insignificante para o sistema social, enlouquece na tentativa de escapar à uma realidade opressora e desumana. Sua única possibilidade de ascender socialmente e alcançar a felicidade se dá através da loucura.

Não obstante, os dois malucos acabam demonstrando um olhar incrivelmente lúcido sobre si mesmos e sobre o mundo em que vivem, o que nos leva a crer que não são assim tão insanos. Há verdade e coerência naquilo que pensam, como se a loucura os incapacitasse de participar dos jogos de aparências que vigoram na sociedade e os fizesse ver as coisas e os homens despidos de suas máscaras. Desse modo, Popróshin ataca os costumes artificiais e tolos da aristocracia petersburguesa e mostra-nos o quão ridículos são os seres humanos em suas ambições. $O$ louco do Cati, por sua vez, ao passar pela revelação que o destino lhe reservava diante das ruínas do "velho castelo", compreende como um homem pode se tornar uma sombra, um vazio, dentro de um contexto de violência.

Por sua insignificância, mas autenticidade, essas personagens despertam nossa empatia e permitem-nos refletir sobre uma questão moral em relação ao outro, sobre a existência humana frente a situações-limite de opressão. Nesse caminho percorrido através das obras literárias, portanto, lidamos com elementos não acabados, ambíguos e que não se definem por uma verdade única. Assim, a filosofia hermenêutica enquanto um modo de ver o mundo, e a perspectiva da tradução enquanto interpretação mostraram-se bastante oportunas para a proposta aqui desenvolvida: a tentativa de outrar-se na construção da compreensão.

\section{Referências}

BEZERRA, Paulo. O laboratório do gênio. In: DOSTOIÉVSKI, Fiódor. O duplo: poema petersburguense. Tradução de Paulo Bezerra. São Paulo: 34, 2013.

CAGGIANI, Ivo. João Francisco: a Hiena do Cati. 2. ed. Porto Alegre: Martins Livreiro, 1997.

CAVALIERE, Arlete. Reflexão crítica. In: GÓGOL, Nicolai. O nariz e A terrível vingança. Tradução de Arlete Cavaliere. São Paulo: Max Limonad, 1986.

CAVALIERE, Arlete. O inspetor geral e o espelho invertido. In: . Teatro russo: Percurso para um estudo da paródia e do grotesco. São Paulo: Humanitas, 2009.

DERRIDA, Jacques. Torres de Babel. Tradução de Junia Barreto. Belo Horizonte: UFMG, 2002.

GADAMER, Hans-Georg. Ler é como traduzir (1989). In: _. Hermenêutica da obra de arte. São Paulo: Martins Fontes, 2010.

GÓGOL, Nikolai. Diário de um louco. In: . $O$ capote e outras novelas. Tradução de Paulo Bezerra. Rio de Janeiro: Civilização brasileira, 1990. 
FOUCAULT, Michel. História da loucura na idade clássica. Tradução de José Teixeira Coelho Netto. 5. ed. São Paulo: Perspectiva, 1997. Coleção Estudos.

FREUD, Sigmund. Conferência XVIII: Fixação em traumas - $\mathrm{O}$ inconsciente. In:_. Obras psicológicas completas: Conferências introdutórias sobre psicanálise - parte III. Tradução de José Luís Meurer. Rio de Janeiro: Imago, 1969. v. XVI.

MACHADO, Dyonelio. O Louco do Cati: (aventura). 5. ed. São Paulo: Planeta do Brasil, 2003.

NESTROVSKI, Arthur; SELIGMANN-SILVA, Márcio (Orgs.). Catástrofe e representação: ensaios. São Paulo: Escuta, 2000.

PALMER, Richard. Hermenêutica. Tradução de Maria Luísa Ribeiro Ferreira. Lisboa: Edições 70, 2011.

SANTOS, Roberson Rosa dos. Diário e delírio na caverna do ciclope. In: SOUZA, Ricardo Timm de; et al. (Orgs.). Literatura e psicanálise: encontros contemporâneos. Porto Alegre: Dublinense, 2012.

STEIN, Ernildo. Aproximações sobre Hermenêutica. Porto Alegre: EDIPUCRS, 1996.

ŽlŽEK, Slavoj. A disciplina entre duas liberdades: loucura e hábito no idealismo alemão. In: GABRIEL, Markus; ŽlŽEK, Slavoj. Mitologia, loucura e riso: a subjetividade no idealismo alemão. Tradução de Silvia Pimenta Velloso Rocha. Rio de Janeiro: Civilização Brasileira, 2012.

ŽlŽEK, Slavoj. Violência: seis reflexões laterais. Tradução de Miguel Serras Pereira. São Paulo: Boitempo, 2014.

\section{COMO CITAR ESSE ARTIGO}

ALMEIDA, Ísis Lopes de; PIAZZA GAI, Eunice Terezinha. Colocar-se na obra literária: uma leitura dos que estão à margem. Signo, Santa Cruz do Sul, v. 45, n. 82, jan. 2020. ISSN 1982-2014. Disponível em: <https://online.unisc.br/seer/index.php/signo/article/view/14220>.

Acesso em: doi:https://doi.org/10.17058/signo.v45i82.14220. 